RESEARCH PAPER

\title{
Genetically decreased CYP2A6 and the risk of tobacco dependence: a prospective study of novice smokers
}

\author{
J O'Loughlin, G Paradis, W Kim, J DiFranza, G Meshefedjian, E McMillan-Davey, S Wong, \\ J Hanley, R F Tyndale
}

Tobacco Control 2004;13:422-428. doi: 10.1136/tc.2003.007070

\begin{abstract}
See end of article for authors' affiliations ....................

Correspondence to: Dr Jennifer O'Loughlin, Department of

Epidemiology, Biostatistics, and Occupational Health, McGill University, 1020

Pine Avenue West, Montréal, Québec, Canada H3A IA3; jennifer.oloughlin@ mcgill.ca
\end{abstract}

Received 5December 2003 Accepted 16 July 2004

\begin{abstract}
Objective: Case control studies in adults suggest that defective alleles in the gene that codes for the hepatic cytochrome P450 2A6 (CYP2A6) protect against nicotine dependence (ND) and higher levels of cigarette consumption. These two hypotheses were tested in young adolescents.

Design: Self reports of tobacco use and ND symptoms were collected every 3-4 months in a prospective study of 1293 grade 7 students from a convenience sample of 10 schools.

Subjects: 281 smokers with genetic data were analysed; those who were not already tobacco dependent and who had inhaled $(\mathrm{n}=228$ ) were followed 29.9 months on average, until they became dependent or were censored.

Main outcome measures: The association between metabolic activity, represented by CYP2A6 genotype, and conversion to dependence was analysed using Cox's proportional hazards model.

Results: During follow up 67 subjects $(29.4 \%)$ became dependent. Relative to CYP2A $6^{*} 1 /{ }^{*} 7$, having $1-2$ copies of the inactive CYP2A $6 * 2$ or * 4 variant was a strong risk factor for developing dependence (hazard ratio $2.8,95 \%$ confidence 1.3 to 6.3 ). Subjects with $1-2$ partially inactive CYP2A6*9 or * 12 variants were not at increased risk. Mean past-week cigarette consumption at the end of follow up (controlling for age, sex, and number of months since first inhalation) among dependent subjects was 29.1 among normal inactivators, compared to 17.2, and 12.7 among slower (1-2 copies of *9 or * 12 ), and slowest (1-2 copies of $* 2$ or $* 4)$ inactivators, respectively $(p=0.09)$.

Conclusion: Adolescents with 1-2 copies of CYP2A6*2 or * 4 are at substantially increased risk of becoming dependent but smoke less once dependent. Genetic risk for ND may need to be considered in the conceptualisation of tobacco control programmes for adolescents.
\end{abstract}

$\mathrm{T}$ he search for determinants of tobacco use initiation and maintenance, the development of nicotine dependence (ND), and levels of cigarette consumption has broadened over the last five years to include a variety of candidate genes, in addition to sociodemographic, psychosocial, and environmental risk factors. ${ }^{1}$ This search is motivated by the belief that information on genetic predisposition and eventually gene-environment interactions will help tailor prevention and cessation interventions to individual need.

Genes involved in the metabolism of nicotine are biologically plausible candidates for studies of smoking behaviour. ${ }^{2}$ In particular, there is considerable inter-individual variation in levels of the genetically polymorphic hepatic enzyme CYP2A6, ${ }^{24}$ which inactivates $80-95 \%$ of nicotine to cotinine. $^{56}$ Seventeen CYP2A6 genetic variants have been identified to date including $C Y P 2 A 6^{*} 1{ }^{*} 16$ and the gene duplication, ${ }^{*} 1 \times 2 .{ }^{47}$ Only a few of these variants, however, have been demonstrated to alter enzymatic function in vivo. The $C Y P 2 A 6^{*} 2$ allele which contains a detrimental point mutation, and CYP $2 A 6^{*} 4$ which contains a gene deletion, are both fully inactive. ${ }^{2}$ Others including $C Y P 2 A 6^{*} 9$ and $C Y P 2 A 6^{*} 12$ result in decreased enzyme activity due to decreased transcription rates and altered enzyme structure, respectively. ${ }^{8}{ }^{9}$

One hypothesis of interest in regard to nicotine metabolism is that slow inactivators of nicotine (that is, individuals with genetic variants of $C Y P 2 A 6$ ) may be less likely to maintain smoking once they have initiated, and thus have a lower risk of developing ND. This is based on the hypothesis that there is little tolerance to the psychoactive effects of nicotine during early onset such that, for the same amount of nicotine inhaled, slow inactivators may experience higher or longer lasting levels of nicotine. This could increase symptoms of nicotine toxicity such as dizziness and nausea, thereby reducing the likelihood of maintaining smoking. ${ }^{10}$ Several case control studies in adults provide support for an association between genetic impairment of CYP2A6 and decreased risk for being tobacco dependent, ${ }^{10-14}$ although others do not. ${ }^{15-17}$

A second hypothesis of interest is that once ND is established, slow inactivators may require fewer cigarettes to maintain nicotine concentrations at optimal levels. Several studies suggest that dependent smokers adjust their smoking to maintain nicotine levels. ${ }^{18}{ }^{19}$ More specifically, smoking is increased if the nicotine content of cigarettes is decreased or if nicotine excretion is increased by urine acidification; smoking is decreased with concurrent intravenous or patch nicotine. ${ }^{2}$ Again several, ${ }^{1320} 21$ but not all ${ }^{14}{ }^{16}{ }^{17}$ studies support the notion that slow nicotine inactivators smoke fewer cigarettes.

In this current analysis of data from a prospective cohort study of young adolescents, we tested the hypothesis that partially or fully inactive CYP2A6 variants protect against early development of tobacco dependence in novice smokers. We also examined early smoking symptoms to determine if slow inactivators experience dizziness and nausea more frequently than normal inactivators, when they first begin to smoke. Finally, we examined if partially or fully inactive CYP2A6 variants protect against higher levels of cigarette consumption.

\section{METHODS}

The McGill University Study on the natural history of nicotine dependence in teens (NDIT study) is an ongoing 
prospective study of 1293 students recruited in fall 1999 from all grade 7 classes in a convenience sample of 10 secondary schools in Montreal. The primary objectives are to study the onset of ND symptoms in relation to first tobacco exposure, and to investigate the relative etiologic importance of environmental and genetic risk factors for ND. Secondary schools were selected to include a mix of French and English schools, urban, suburban, and rural schools, and schools located in high and low socioeconomic neighbourhoods. All subjects and a parent/guardian provided written, informed consent. Over half $(55.4 \%)$ of eligible students participated in the baseline data collection; the low response is related in part to the need for a blood draw for genetic analysis, and also to a labour dispute in Quebec schools during baseline data collection which affected the collection of consent forms. The McGill University Faculty of Medicine Institutional Review Board approved the study protocol.

Data collection comprised self report questionnaires administered at school every 3-4 months during the school year. A blood draw for DNA analysis was completed in March 2002; 561 of 1054 eligible subjects $(53.2 \%)$ provided written parental consent for the blood draw. Blood specimens were available for 523 subjects, of whom 281 (53.7\%) were white (we restricted the DNA analysis to white subjects) and had initiated cigarette smoking either before the first wave of data collection (hereafter called "baseline smokers") or during follow up (hereafter called "initiators").

Lifetime smoking history was determined at each follow up in two items adapted from previous research. ${ }^{22}$ Six items measured smoking in a three month recall beginning with the month preceding questionnaire administration ${ }^{23}$; one item for each month measured the number of days on which the subject had smoked during the month, and one item for each month measured the number of cigarettes smoked per day on average during that month. The number of cigarettes smoked during the week preceding questionnaire administration was measured in a seven day recall. ${ }^{24}$ Age at first inhalation was ascertained among subjects who reported that they had inhaled.

Early smoking symptoms of nicotine toxicity were assessed by asking subjects whether they had experienced each of dizziness and nausea a lot, a bit, or not at all the first few times they took cigarette smoke into their lungs. Data for these variables were drawn from the first questionnaire completed among baseline smokers, and from the first questionnaire in which the subjects reported inhaling among initiators.

Our measure of tobacco dependence included 2-4 items for each of the six criteria of the International classification of diseases, 10th revision (ICD-10) definition of tobacco dependence, for a total of 18 items. ${ }^{25}$ Each item had multiple response choices; an item was considered positive only if the most extreme positive response choice was endorsed. A criterion was considered positive if any of its items was positive (the withdrawal syndrome required that two or more of four items be endorsed). A subject was categorised as tobacco dependent (yes, no) if he/she met three or more of the six ICD-10 criteria. In previous work, ${ }^{26}$ internal reliability and two week test retest reliability of the ICD-10 measure were excellent (Cronbach's $\alpha=0.91,100 \%$ test retest agreement), and in addition the measure showed strong evidence of convergent construct validity.

\section{Genotyping}

Genotyping was performed for five variant alleles using established methods based on gene and allele-specific two step polymerase chain reaction (PCR) assays. ${ }^{4}{ }^{11}$ The variants investigated were selected based on their impact on nicotine metabolism and on reported frequencies in whites. ${ }^{4}$ The analyses identified two partially inactive variants $\left(C Y P 2 A 6^{*} 9,{ }^{*} 12\right)$, two fully inactive variants $\left(C Y P 2 A 6^{*} 2,{ }^{*} 4\right)$, and the increased activity gene duplication, $C Y P 2 A 6^{*} 1 \times 2$.

\section{Data analysis}

The sample included 281 white baseline smokers and initiators with venepuncture. Subjects were categorised into three groupings according to genotype including normal inactivators (two copies of ${ }^{*} 1$, the wild type active allele), slower inactivators ( $1-2$ copies of ${ }^{*} 9$ or * 12 , or one copy each of ${ }^{*} 9$ and ${ }^{*} 12$ ) and slowest inactivators (1-2 copies of ${ }^{*} 2$ or *4). Data for this analysis were drawn from the first four years of follow up.

To estimate the incidence of conversion to tobacco dependence, subjects were followed from time of first inhalation until they became dependent or until they were censored (lost to follow up or study period ended). The association between the rate of conversion to dependence and the presence of defective relative to normal variants was examined in Kaplan-Meier actuarial analysis. Hazard ratios for the development of dependence for each genotype category relative to the $C Y P 2 A 6^{*} 1 /{ }^{*} l$ genotype were derived from Cox's proportional hazards model. Because they were more comparable with respect to bias related to recall of age at first inhalation, ever smokers and initiators were analysed in separate strata.

To examine if bias related to recall of age at first inhalation affected parameter estimates, we restricted a second analysis to subjects who reported their first inhalation after the baseline. Subjects were followed from the time of first inhalation until they converted to dependence or until they were censored.

\section{Role of the funding source}

The study sponsor had no role in the study design, collection, analysis, and interpretation of data, in the writing of the report, or in the decision to submit the paper for publication.

\section{RESULTS}

Overall $12.8 \%$ of subjects had one or two copies of partially inactive CYP2A6 variants ${ }^{*} 9$ or ${ }^{*} 12 ; 6.4 \%$ had one or two copies of inactive variants ${ }^{*} 2$ or ${ }^{*} 4$ (table 1 ). There were no important differences in the distribution of these variants by sex, age, or language. Hardy-Weinberg computations indicated that the observed genotype distribution was not different from the expected distribution, indicating no evidence of non-random selection.

There were fewer smokers among subjects with venepuncture than among those without venepuncture $(28.2 \% \quad v$ $35.1 \%)$. Compared to never smokers with venepuncture, there were higher proportions of females $(59.8 \% v 42.6 \%)$, of Francophones $(33.0 \% \vee 24.0 \%)$, of subjects whose mothers smoked $(32.4 \% \vee 12.0 \%)$, and of subjects whose fathers smoked $(30.8 \% \vee 18.7 \%)$ among ever smokers with venepuncture. table 2 shows selected characteristics of subjects included in the current analysis. The prevalence of smoking among parents of subjects with at least one copy of inactive CYP2A6 variants was notably lower than among parents of other subjects. Contrary to the study hypothesis, slow inactivators did not report more early smoking symptoms of dizziness or nausea than normal inactivators (table 2).

Fifty three subjects were not at risk of developing tobacco dependence either because they were already dependent at baseline $(\mathrm{n}=7)$ or because they had never inhaled ( $\mathrm{n}=46)$; these subjects were excluded from further analysis. Ten of the 228 subjects retained for further analysis were lost to follow up; one subject dropped out and nine moved. 
Table 1 Distribution of genotype according to metabolic activity among all subjects, those who had inhaled, and those who initiated inhalation during follow up

\begin{tabular}{|c|c|c|c|c|c|c|}
\hline \multirow{2}{*}{$\begin{array}{l}\text { Metabolic activity } \\
\text { and genotype }\end{array}$} & \multicolumn{2}{|c|}{ All subjects† } & \multicolumn{2}{|c|}{$\begin{array}{l}\text { Subjects who had } \\
\text { inhaled } \neq\end{array}$} & \multicolumn{2}{|c|}{$\begin{array}{l}\text { Subjects who initiated inhalation } \\
\text { during follow up } \S\end{array}$} \\
\hline & $\mathbf{n}$ & $\%$ & $\mathbf{n}$ & $\%$ & $\bar{n}$ & $\%$ \\
\hline Total & 281 & 100.0 & 228 & 100.0 & 151 & 100.0 \\
\hline Normal inactivators & 227 & 80.8 & 188 & 82.5 & 118 & 78.2 \\
\hline${ }^{*} 1 /{ }^{*} 7$ & 226 & & 188 & & 118 & \\
\hline$* 1 / * 7 \times 2$ & 1 & & 0 & & 0 & \\
\hline Slower inactivators & 36 & 12.8 & 26 & 11.4 & 21 & 13.9 \\
\hline${ }^{*} 7 /{ }^{*} 12$ & 5 & & 3 & & 3 & \\
\hline$* 7 / * 9$ & 28 & & 21 & & 16 & \\
\hline *9/*9 & 2 & & 1 & & 1 & \\
\hline$* 9 / * 12$ & 1 & & 1 & & 1 & \\
\hline Slowest inactivators & 18 & 6.4 & 14 & 6.1 & 12 & 8.0 \\
\hline$* 4 / * 9$ & 1 & & 0 & & 0 & \\
\hline$* 7 / * 2$ & 11 & & 9 & & 7 & \\
\hline$* 2 / * 9$ & 4 & & 3 & & 3 & \\
\hline${ }^{*} 2 /{ }^{*} 2$ & 2 & & 2 & & 2 & \\
\hline \multicolumn{7}{|c|}{$\begin{array}{l}\text { tIncludes subjects who inhaled before baseline, those who initiated inhalation during follow up, and those whe } \\
\text { never inhaled. } \\
\text { flncludes subjects who inhaled before baseline and those who initiated inhalation during follow up. } \\
\text { §lncludes subjects who initiated inhalation during follow up. }\end{array}$} \\
\hline
\end{tabular}

Over an average 29.9 (SD 20.7) month follow up from time of first inhalation, 67 of 228 subjects (29.4\%) became tobacco dependent. The incidence of conversion was substantially higher among the slowest inactivators, compared to other subjects (table 3). Figure 1 compares Kaplan-Meier curves according to genotype. The Cox's proportional hazard ratios confirmed the Kaplan-Meier analysis and suggested that the risk of conversion was almost three times higher among the slowest inactivators relative to normal inactivators (hazard ratio (HR) 2.8, 95\% confidence interval (CI) 1.3 to 6.3 ) (table 3).

In an analysis restricted to the 151 subjects who initiated inhalation after the baseline data collection (table 3, fig 2), the risk of conversion for the slowest inactivators remained significant (HR 3.2, 95\% CI 1.3 to 7.7 ).

To test if the partially inactive or inactive CYP2A6 variants protect against higher levels of cigarette consumption, we compared past week cigarette consumption at the end of follow up among dependent and non-dependent subjects by genotype, controlling for age, sex, and months since first inhalation. There was a non-significant trend toward lower cigarette consumption among slowest and slower inactivators who were dependent compared with dependent normal inactivators $(12.7,17.2$, and 29.1 cigarettes in the past week, respectively (table 4 ); median $=11.5,16$, and 21 cigarettes in the past week).

\section{DISCUSSION}

Recent studies suggest that early ND symptoms play a central role in novice smokers maintaining the smoking habit and becoming addicted to tobacco, ${ }^{27}{ }^{28}$ and it is well established that ND is associated with smoking cessation failures. However, although there is substantial genetic risk for several aspects of smoking, including the development of ND and the amount smoked, ${ }^{1}$ no studies to date have investigated genetic risk prospectively in novice smokers.

Defective CYP2A6 alleles are promising candidate determinants from a biological perspective, although case-control

\begin{tabular}{|c|c|c|c|}
\hline & $\begin{array}{l}\text { Normal inactivators } \\
(\mathrm{n}=227)\end{array}$ & $\begin{array}{l}\text { Slower inactivators } \\
(n=36)\end{array}$ & $\begin{array}{l}\text { Slowest inactivators } \\
(\mathrm{n}=18)\end{array}$ \\
\hline Male (\%) & 39.7 & 47.2 & 33.3 \\
\hline Age (y) at baseline, mean (SD)* & $12.8(0.6)$ & $12.8(0.4)$ & $12.6(0.4)$ \\
\hline Francophone (\%) & 33.8 & 25.0 & 38.9 \\
\hline Single parent family (\%) & 7.1 & 8.3 & 11.1 \\
\hline \multicolumn{4}{|l|}{ University educated (\%) } \\
\hline Mother & 37.6 & 51.5 & 47.1 \\
\hline Father & 42.6 & 46.9 & 35.3 \\
\hline \multicolumn{4}{|l|}{ Household income (CAN\$), } \\
\hline $\begin{array}{l}\text { mean (SD) } \\
\text { Ever smoked at baseline }(\%)\end{array}$ & $\begin{array}{l}61032(21796) \\
502\end{array}$ & $\begin{array}{l}70125(24659) \\
50.0\end{array}$ & $\begin{array}{l}59292(19709) \\
38.9\end{array}$ \\
\hline $\begin{array}{l}\text { Ever smoked at baseline (\%) } \\
\text { Ever inhaled (\%) }\end{array}$ & $\begin{array}{l}50.2 \\
85.0\end{array}$ & 75.0 & $\begin{array}{l}38.9 \\
83.3\end{array}$ \\
\hline $\begin{array}{l}\text { Age }(y) \text { at first inhalation, } \\
\text { mean (SD)† } \\
\text { Early smoking symptoms (\%)† }\end{array}$ & $12.9(1.7)$ & $13.2(1.6)$ & $13.3(1.9)$ \\
\hline Dizziness & 36.8 & 25.9 & 33.3 \\
\hline Nausea & 14.5 & 7.4 & 20.0 \\
\hline \multicolumn{4}{|l|}{ Parental smoking \% } \\
\hline Mother & 35.0 & 22.9 & 17.7 \\
\hline Father & 30.0 & 41.2 & 18.8 \\
\hline $\begin{array}{l}\text { *Standard deviation. } \\
\text { †Among subjects who had ever } \\
\text { p Values were obtained from } \chi\end{array}$ & led $(n=193$ normo & $\begin{array}{l}\text { ower, and } 15 \text { slov } \\
\text { associations teste }\end{array}$ & $\begin{array}{l}\text { nactivators, respective } \\
\text { e significant). }\end{array}$ \\
\hline
\end{tabular}


Table 3 Incidence and hazard ratio of conversion to tobacco dependence according to metabolic activity

\begin{tabular}{|c|c|c|c|c|}
\hline \multirow{2}{*}{$\begin{array}{l}\text { Metabolic } \\
\text { activity }\end{array}$} & \multicolumn{2}{|c|}{ All subjects who had inhaled ( $n=228$ ) } & \multicolumn{2}{|c|}{ Initiated inhalation during follow up $(n=151)$} \\
\hline & Incidence $(95 \% \mathrm{Cl}) \dagger$ & HR $(95 \% \mathrm{Cl}) \ddagger$ & Incidence $(95 \% \mathrm{Cl})$ & $\operatorname{HR}(95 \% \mathrm{Cl})$ \\
\hline Total $^{*}$ & 9.8 (7.6 to 12.5$)$ & - & 12.3 (8.7 to 16.9 ) & - \\
\hline $\begin{array}{l}\text { Normal } \\
\text { inactivators }\end{array}$ & 9.1 (6.8 to 11.9 ) & Ref & $11.0(7.2$ to 16.0$)$ & Ref \\
\hline $\begin{array}{l}\text { Slower } \\
\text { inactivators }\end{array}$ & 10.0 (4.0 to 20.6$)$ & $1.1(0.5$ to 2.5$)$ & 10.7 (3.4 to 24.9$)$ & $1.00(0.4$ to 2.5$)$ \\
\hline $\begin{array}{l}\text { Slowest } \\
\text { inactivators }\end{array}$ & $25.2(10.1$ to 51.8$)$ & $2.8(1.3$ to 6.3$)$ & 38.5 (14.1 to 84.0$)$ & $3.2(1.3$ to 7.7$)$ \\
\hline
\end{tabular}

*Excludes 7 subjects who were ICD-10 tobacco dependent at baseline, and 46 subjects who had never inhaled. †Number of subjects who became tobacco dependent per 1000 person-months. †Hazard ratio and $95 \%$ confidence intervals from Cox's proportional hazards models.

studies of adults yield conflicting results. Inherent difficulties in these studies including bias related to population stratification, cases and controls drawn from different populations, crude phenotype assessments, undetermined co-morbidity, variable genotyping methodologies, examination of different variant alleles, and poor recall of smoking history, cigarette consumption, and symptoms of nicotine dependence, could explain the lack of replication. ${ }^{3}$ In this current study, we minimised recall bias by studying conversion to dependence in a prospective study of healthy young novice smokers, and we reduced misclassification bias by using a validated measure of tobacco dependence with strong psychometric properties. Although this is the first study of CYP2A6 in adolescents there is little reason to suspect that nicotine metabolism, or the effects of variant and non-variant alleles in this age group, differ from that observed in adults. Gourlay and Benowitz ${ }^{29}$ reported no differences in steady state nicotine plasma concentrations or estimated plasma clearance values in three age groups (18-39, 40-59, and 6069 years) following application of nicotine patches. The half life of cotinine, which is metabolised exclusively by CYP2A6, is similar in neonates, older children, and adults. ${ }^{30}{ }^{31}$ Finally other CYP2A6 substrates such as coumarin and caffeine are metabolised similarly in children of different ages and adults. ${ }^{32-34}$

Despite the evidence in adults, none of the defective CYP2A6 variants investigated in this study protected subjects from developing dependence. In contrast having 1-2 copies of an inactive variant increased the risk substantially. It thus seems possible that slow nicotine inactivation results in prolonged and/or higher brain exposure to nicotine, and that this more intense exposure might enhance the neurophysiological processes that lead to dependence. It is possible that even very brief exposures to nicotine during adolescence can result in long term neurological adaptations. Abreu-Villaca et $a l^{35}$ demonstrated an increase in the number of nicotinic acetylcholine receptors in the hippocampus of adolescent rats in response to four injections of nicotine, which is equivalent to smoking two cigarettes on two consecutive days. We postulate that genetic alterations that slow nicotine metabolism increase the likelihood that the first few cigarettes smoked by an adolescent will initiate the neurological alterations that lead to dependence.

In addition to difficulties in the case-control design, another explanation for our findings relative to adult casecontrol studies is that genetically slow nicotine metabolism has different effects at different stages of smoking. It may be detrimental by increasing the risk for becoming dependent in novice smokers, but beneficial by increasing the ability to quit smoking in established smokers. In fact the proportion of slow metabolisers among adult current smokers decreases with duration of smoking, ${ }^{11}$ suggesting that slow metabolisers might quit more readily than normal metabolisers. Gu et $a l^{13}$ reported that white adults with CYP2A6*2 alleles smoked for a shorter duration and were 1.75 (95\% CI 1.17 to 2.61 ) times more likely to quit relative to adults with no $C Y P 2 A 6^{*} 2$ allele. Similar findings have also been observed among African Americans. ${ }^{36}$ Finally, slower metabolisers in this

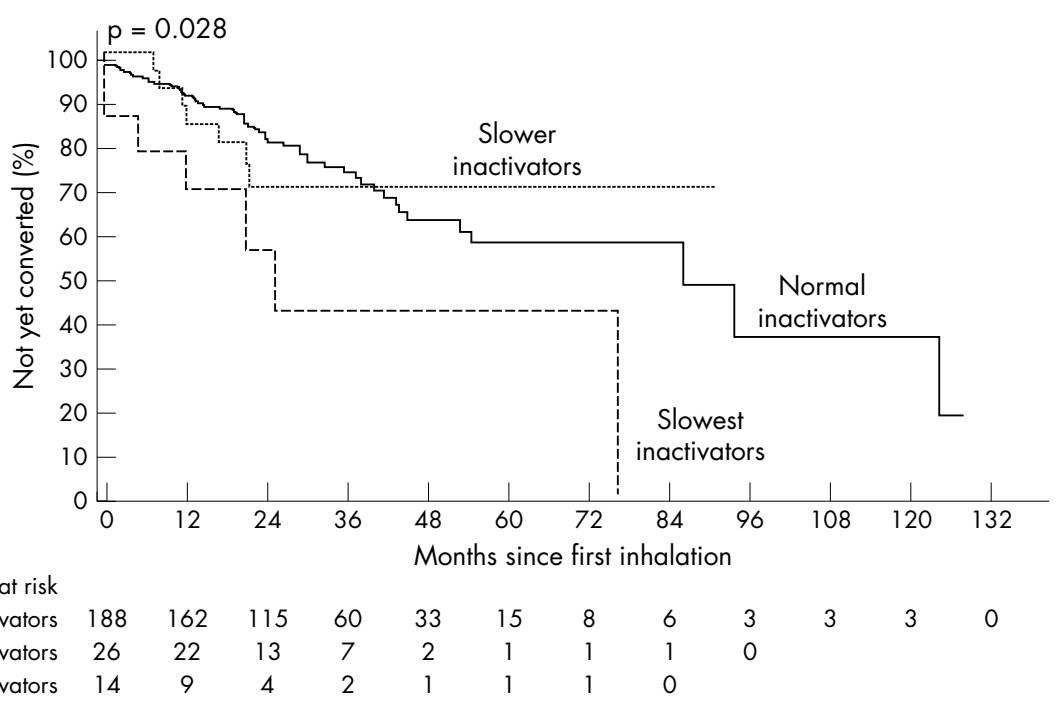

Figure 1 Actuarial estimates of conversion to ICD-10 tobacco dependence according to metabolic activity among subjects who had inhaled $(n=228)$. The $p$ value was calculated with the use of the log rank test.

Number at risk

Normal inactivators

Slower inactivators

Slowest inactivators

26
14

13




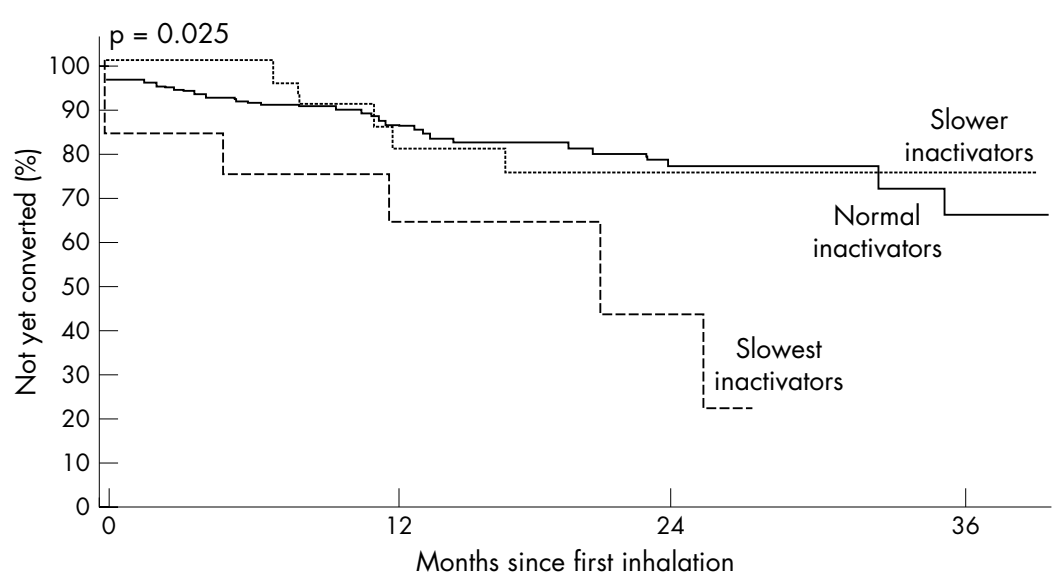

Figure 2 Actuarial estimates of conversion to ICD-10 tobacco dependence according to metabolic activity among subjects who initiated inhalation during follow up $(n=151)$.

The $p$ value was calculated with the use of the log rank test.

Number at risk

93

17
55

10
10

4 current study smoked fewer cigarettes per week, and lower cigarette consumption has been associated in studies of adults with better cessation outcomes. ${ }^{37}{ }^{38}$ It is possible that under-representation of adult smokers with CYP2A6 genetically mediated slow nicotine inactivation who have quit smoking (selection bias), or possibly misclassification of smokers who have quit, results in an apparent protective effect of slow metabolism in adult case-control studies. Our observation of a lower prevalence of smoking among parents of slow inactivators is consistent with this reasoning.

According to our hypotheses, symptoms associated with early smoking act in the causal pathway between genotype and tobacco dependence. Because of a presumed aversive reaction to these symptoms, subjects with defective alleles were hypothesised to avoid cigarettes, thus minimising the risk of becoming dependent. Our data do not support the hypothesis that higher circulating concentrations of nicotine represented by genotype are associated with increased early smoking symptoms of dizziness or nausea. Therefore it is unlikely that, even if defective alleles were protective against developing ND, this association is mediated through symptoms associated with early smoking.

Consistent with our observations in this study, previously reported prevalences of $C Y P 2 A 6^{*} 9$ and ${ }^{*} 12$ alleles are $5.2 \%$ and $2.2 \%$, respectively, in whites. ${ }^{4}{ }^{11}$ Similarly approximately $6 \%$ of study subjects in this sample had a genotype which included at least one copy of the CYP $2 A 6^{*} 2$ or ${ }^{*} 4$ variant. The population attributable risk $(\mathrm{PAR} \%=\mathrm{p}(\mathrm{RR}-1) /(\mathrm{p}(\mathrm{RR}-$ 1) +1$) \times 100$ ) related to the $C Y P 2 A 6^{*} 2$ or ${ }^{*} 4$ variants among white adolescent ever smokers is therefore in the range of $14.6 \%$, indicating that this genetic predisposition is a public health issue that warrants attention.

Previous reports suggest that defective CYP2A6 variants protect against heavy tobacco use. ${ }^{11}{ }^{132021}$ Our data show that cigarette consumption at the end of follow up was notably lower among dependent subjects with reduced activity alleles. This is consistent with the notion that slow metabolism results in sustained high exposure to nicotine and therefore subjects with defective alleles require fewer cigarettes to maintain nicotine concentrations at optimal levels.

Overall these data provide compelling evidence for genetic influences in the development of ND and possibly levels of cigarette consumption. However, because most novice smokers are intermittent smokers with low cigarette consumption, we need to better understand how defective CYP2A6 genotypes affect peak nicotine concentrations after a single cigarette, and how long nicotine remains after smoking a single cigarette. As suggested above, it is possible that following the initial phase of intake of nicotine from a single cigarette, the plasma and brain concentrations of nicotine decrease more slowly in slow metabolisers resulting in higher and longer retention of nicotine in blood and brain concentrations. If a second cigarette is smoked within hours

\begin{tabular}{|c|c|c|c|c|c|c|}
\hline \multirow[b]{3}{*}{ Metabolic activity } & \multirow{2}{*}{\multicolumn{2}{|c|}{ Total }} & \multicolumn{4}{|c|}{ ICD-10 dependent } \\
\hline & & & \multicolumn{2}{|l|}{ Yes } & \multicolumn{2}{|l|}{ No } \\
\hline & $n$ & Mean $(\mathrm{SE})^{*}$ & $n$ & Mean (SE) & $n$ & Mean (SE) \\
\hline Total & 151 & $8.0(1.3)$ & 38 & $23.9(3.6)$ & 113 & $2.7(0.9)$ \\
\hline Normal inactivators & 118 & $8.6(1.6)$ & 27 & $29.1(4.7)$ & 72 & $2.9(1.0)$ \\
\hline Slower inactivators & 21 & $7.4(3.7)$ & 5 & $17.2(11.1)$ & & $4.1(2.4)$ \\
\hline $\begin{array}{l}\text { Slowest inactivators } \\
\text { p Value† }\end{array}$ & $\begin{array}{l}12 \\
0.410\end{array}$ & $3.3(4.9)$ & $\begin{array}{l}6 \\
0.090\end{array}$ & $12.7(10.3)$ & $\begin{array}{l}3 \\
0.881\end{array}$ & $0.9(3.9)$ \\
\hline \multicolumn{7}{|c|}{$\begin{array}{l}\text { *Last square mean (standard error (SE)) based on analysis of variance (ANOVA) controlling for age, sex, and } \\
\text { number of months since first inhalation. } \\
t p \text { Value, based on the } \mathrm{F} \text { test in ANOVA, compares normal with slower and slowest inactivators combined } \\
\text { controlling for age, sex, and number of months since first inhalation. }\end{array}$} \\
\hline
\end{tabular}




\section{What this paper adds}

Several, although not all, case-control studies in adults provide support for an association between genetic impairment of CYP2A6 and decreased risk for being tobacco dependent. However, inherent difficulties in the case-control design include bias related to population stratification, cases and controls drawn from different populations, crude phenotype assessments, undetermined co-morbidity, variable genotyping methodologies, examination of different variant alleles, and poor recall of smoking history, cigarette consumption, and symptoms of nicotine dependence. In this prospective study of novice smokers, we showed that adolescents with 1-2 copies of CYP2A $6^{*} 2$ or * 4 are at substantially increased risk of becoming dependent, raising concerns that genetic risk for nicotine dependence may need to be considered in the conceptualisation of tobacco control programmes for adolescents.

the peak blood concentrations could be higher due to the higher blood concentrations that exist before the second cigarette is smoked. There is also a need for continued assessment of adolescents through the later stages of smoking. More specifically, the stage of smoking at which slow nicotine inactivation might begin to confer an advantage with respect to quitting should be determined.

\section{Study limitations}

The subjects retained for analysis represent a distinct subgroup of the larger sample. It included (1) only white subjects, (2) only subjects who consented and participated in the blood draw; and (3) among subjects with blood draw, only those who had initiated smoking. We did not genotype all subjects with blood draw because of budget restrictions. While subjects retained for analysis represent fewer that 25\% of the sample, it is unlikely that this biased the main findings on the association between genotype and onset of dependence-refusal to participate in the blood draw (or in the overall study) is not likely to relate to genotype because all potential participants were unaware of their CYP2A6 status.

The sample size of subjects with the inactive CYP2A $6^{*} 2$ or * 4 variants who became tobacco dependent was small, but this did not impede detection of a significant association between these variants and conversion to tobacco dependence. Data on ICD-10 symptoms of tobacco dependence were drawn from self reports by adolescents. However, our ICD-10 indicator has been shown to be internally reliable, to have excellent test retest reliability, and to show convergent construct validity. ${ }^{26}$ Although the proportion of subjects with blood draw was modest, there were few meaningful significant differences between subjects retained and those not retained for this analysis. In addition, because loss to follow up was minimal, there is little reason to suspect that selection bias affected the results, or that external generalisability is an issue of concern.

\section{Conclusion}

Adolescents with slowed nicotine metabolism due to genetic defects in CYP2A6 are at substantially increased risk of becoming tobacco dependent at relatively low levels of cigarette consumption. The role that genetically mediated slow nicotine inactivation may have at different stages of smoking (that is, development of dependence, success in cessation) needs to be clarified. Consistent with adult studies, adolescents with slow nicotine inactivation smoke less than normal inactivators. Overall these data suggest that genetic risk for ND should be taken into account in the conceptualisation of prevention and cessation programmes for adolescents.

\section{ACKNOWLEDGEMENTS}

This research was funded by the National Cancer Institute of Canada with funds from the Canadian Cancer Society. J O'Loughlin is an Investigator of the Canadian Institutes of Health Research. We acknowledge the support of a Canadian Institutes of Health Research Tobacco Research Training award to W Kim and a Canadian Research Chair in Pharmacogenetics to RF Tyndale. The genotyping was funded in part by CIHR grant MOP 53248 to RF Tyndale and by the Centre for Addiction and Mental Health. The authors thank G Chong for the DNA extraction, PBS Clarke for comments on the manuscript, and $\mathrm{B} \mathrm{Xu}$ for invaluable technical support.

\section{Authors' affiliations}

J O'Loughlin*, G Paradis*, J Hanley, Department of Epidemiology, Biostatistics, and Occupational Health, McGill University, Montréal, Québec, Canada

G Meshefedjian, E McMillan-Davey, Direction de santé publique de Montréal-Centre, Montréal, Québec, Canada

J DiFranza, Department of Family Medicine and Community Health, University of Massachusetts Medical School, Worcester, Massachusetts, USA

W Kim, S Wong, R F Tyndale, Centre for Addictions and Mental Health, Department of Pharmacology, University of Toronto, Toronto, Ontario, Canada

*Also Direction de santé publique de Montréal-Centre, Montréal, Québec, Canada

\section{REFERENCES}

1 Tyndale RF. Genetics of Alcoholism and Tobacco Use in Humans. Ann Med 2003;35:94-121.

2 Tyndale RF, Sellers EM. Genetic variation in CYP2A6-mediated nicotine metabolism alters smoking behavior. Ther Drug Monit 2002;24:163-71.

3 Lerman C, Niaura. Applying genetic approaches to the treatment of nicotine dependence. Oncogene 2002;21:7412-20.

4 Xu C, Goodz S, Sellers EM, et al. CYP2A6 genetic variation and potential consequences. Adv Drug Deliv Rev 2002;54:1245-56.

5 Benowitz NL, Jacob P 3rd. etabolism of nicotine to cotinine studied by a dual stable isotope method. Clin Pharmacol Ther 1994;56:483-93.

6 Messina ES, Tyndale RF, Sellers EM. A major role for CYP2A6 in nicotine Coxidation by human liver microsomes. J Pharmacol Exp Ther 1997;282:1608-14

7 Human Cytochrome P450 (CYP) Allele Nomeuclature Committee. http:// www.imm.ki.se/CYPalleles/cyp2a6.htm.

8 Yoshida R, Nakajima M, Nishimura K, et al. Effects of polymorphism in promoter region of human CYP2A6 gene (CYP2A6*9) on expression level of messenger ribonucleic acid and enzymatic activity in vivo and in vitro. Clin Pharmacol Ther 2003;74:69-76.

9 Oscarson M, McLellan RA, Asp V, et al. Characterization of a novel CYP2A7/ CYP2A6 hybrid allele (CYP2A $6 * 12$ ) that causes reduced CYP2A6 activity. Hum Mutat 2002;20:275-83.

10 Pianezza M, Sellers $E$, Tyndale R. A common genetic defect in nicotine metabolism decreases smoking. Nature 1998;393:750.

11 Schoedel KA, Hoffmann EB, Xu B, et al. Ethnic variation in CYP2A6 and association of genetically slow nicotine metabolism and smoking in adult Caucasians. Pharmacogenetics (in press).

12 Farooq, Ferrence R, Tyndale RF, et al. The role of cytochrome P450 2A6*4 in relation to cigarette smoking behaviour and lung cancer case-control status. Society for Research on Nicotine and Tobacco. New Orleans, 2003.

13 Gu DF, Hinks $\sqcup$, Morton NE, et al. The use of long PCR to confirm three common alleles at the CYP2A6 locus and the relationship between genotype and smoking habit. Ann Hum Genet 2000;64:383-90.

14 Ando M, Hamajima N, Ariyoshi N, et al. Association of CYP2A6 gene deletion with cigarette smoking status in Japanese adults. J Epidemiol 2003;13:176-81.

15 Loriot MA, Rebuissou S, Oscarson M, et al. Genetic polymorphisms of cytochrome P450 2A6 in a case-control study on lung cancer in a French population. Pharmacogenetics 2001;11:39-44.

16 Tiihonen J, Pesonen U, Kauhanen J, et al. CYP2A6 genotype and smoking Mol Psychiatry 2000;5:347-8.

17 Zhang $X$, Amemo K, Ameno S, et al. Lack of association between smoking and CYP2A6 gene polymorphisms in A Japanese population. Nihon Arukoru Yakubutsu Igakkai Zasshi 2001;36:486-90.

18 Russell MAH. Nicotine intake and its regulation by smokers. In: Advances in behavioral biology - tobacco, smoking and nicotine, In: Martin WR,

Vauhon GR, Iwamoto ET, David L, eds. New York: Plenum, 1987:25-50.

19 Scherer G. Smoking behavior and compensation: a review of the literature. Psychopharmacology 1999;145:1-20. 
20 Rao Y, Hoffmann E, Zia M, et al. Duplications and defects in the CYP2A6 gene: identification, genotyping, and in vivo effects on smoking. Mol Pharmacol 2000;58:747-55.

21 Minematsu N, Nakamura $\mathrm{H}$, Iwata $\mathrm{M}$, et al. Association of CYP2A6 deletion polymorphism with smoking habit and development of pulmonary emphysema. Thorax 2003;58:623-8.

22 Flynn BS, Worden JK, Secker-Walker RH, et al. Prevention of cigarette smoking through mass media intervention and school programs. Am J Public Health 1992;82:827-33

23 Centers for Disease Control and Prevention. Selected cigarette smoking initiation and quitting behaviors among high school students-United States, 1997. MMWR Morb Mortal Wkly Rep 1998:47:386-9.

24 Stephens T, Morin M, eds (Health Canada). Youth Smoking Survey, 1994: Technical Report. Ottawa: Minister of Supply and Services Canada, 1996 (Catalogue No, H49-98/1-1994E).

25 World Health Organization. International statistical classification of diseases and related health problems, 10th revision. Geneva: WHO, 1992.

26 O'Loughlin J, Difranza J, Tarasuk J, et al. Assessment of nicotine dependence symptoms in adolescents: a comparison of five indicators. Tobacco Control 2002:11:354-60.

27 Difranza JR, Savageau JA, Rigotti NA, et al. Development of symptoms of tobacco dependence in youths: 30 month follow up data from the DANDY study. Tobacco Control 2002;3:228-35.

28 O'Loughlin J, DiFranza J, Tyndale RF, et al. Nicotine dependence symptoms are associated with smoking frequency in adolescents. Am J Prev Med 2003;25:219-25.
29 Gourlay SG, Benowitz NL. The benefits of stopping smoking and the role of nicotine replacement therapy in older patients. Drugs Aging 1996;9:8-23.

30 Leong JW, Dore ND, Shelley K, et al. The elimination half-life of urinary cotinine in children of tobacco-smoking mothers. Pulm Pharmacol Ther 1998; 11:287-90.

31 Dempsey D, Jacob P 3rd, Benowitz NL. icotine metabolism and elimination kinetics in newborns. Clin Pharmacol Ther 2000;67:458-65.

32 Willers S, Skarping G, Dalene $M$, et al. Urinary cotinine in children and adults during and after semiexperimental exposure to environmental tobacco smoke. Arch Environ Health 1995;50:130-8.

33 Pasanen M, Rannala Z, Tooming A, et al. Hepatitis A impairs the function of human hepatic CYP2A6 in vivo. Toxicology 1997; 123:177-84.

$34 \mathrm{Krul} \mathrm{C}$, Hageman G. Analysis of urinary caffeine metabolites to assess biotransformation enzyme activities by reversed-phase high-performance liquid chromatography. J Chromatogr B Biomed Sci Appl 1998;709:27-34

35 Abreu-Villaca YA, Seidler FJ, Qiao D, et al. Short-term adolescent nicotine exposure has immediate and persistent effects on cholinergic systems: critical periods, patterns of exposure, dose thresholds. Neuropsychopharmacology 2003;28:1935-49.

36 Goodz S, Alhuwalia J, Harris K, et al. CYP2A6 genetic variants among African Americans. Society for Research on Nicotine and Tobacco, Abstract, Savannah Georgia, 2002.

37 Breslau N, Johnson EO. Predicting smoking cessation and major depression in nicotine-dependent smokers. Am J Public Health 2000;90:1122-7.

38 Hymowitz N, Cummings KM, Hyland A, et al. Predictors of smoking cessation in a cohort of adult smokers followed for five years. Tobacco Control 1997:6(suppl 2):S57-62.

\section{The Lighter Side}

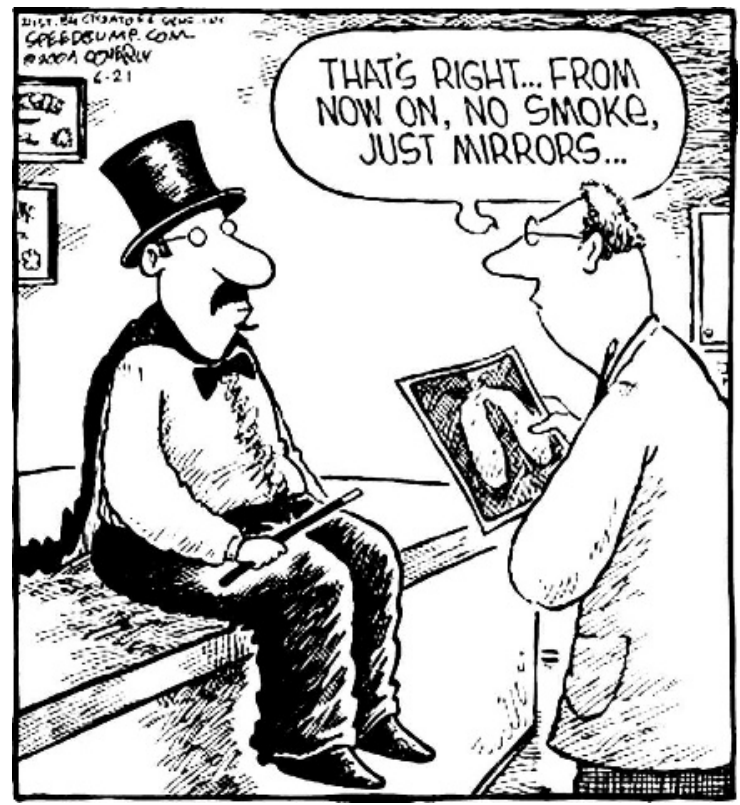

( ) Speed Bump. By permission of Dave Coverly and Creators Syndicate, Inc. 